\title{
Effect of Co Addition on Microstructure in High Cr Ferritic Steels
}

\author{
Katsumi YAMADA, Masaaki IGARASHI, ${ }^{1)}$ Seiichi MUNEKI') and Fujio ABE ${ }^{2)}$ \\ JFE Steel Corporation, 1-1 Minamiwatarida-cho, Kawasaki-ku, Kawasaki, Kanagawa 210-0855 Japan. \\ 1) Sumitomo Metal Industries, Ltd., 1-8 Fuso-cho, Amagasaki, Hyogo 660-0891 Japan. \\ 2) National Institute for Materials Science, 1-2-1 Sengen, Tsukuba, Ibaraki 305-0047 Japan.
}

(Received on November 26, 2002; accepted in final form on March 13, 2003)

\begin{abstract}
Co is one of the interesting alloying elements in advanced high $\mathrm{Cr}$ ferritic steels used to improve their creep properties at elevated temperatures. However, it has been reported that Co bearing tends toward rapid deterioration in creep property at long-term testing. In this study, microstructures were studied in detail by comparing two kinds of $9 \% \mathrm{Cr}$ ferritic steels with $3 \%$ Co and Co free for better understanding difference in those creep behaviors.

Creep property of the steel with $3 \%$ Co was superior to that of the steel without Co within this study, as many researchers pointed out. Adding Co certainly suppressed $\delta$-ferrite formation and there was large difference in prior-austenite grain size between two steels after tempering. In addition to this macroscopic difference, there was also remarkable change in precipitation behavior between them. It was found that heterogeneous precipitation of inter-metallic compounds and $\mathrm{MX}$ type carbonitrides was observed in Co free steel, while any extreme localization of such precipitation were not seen in $3 \%$ Co steel.

It was deduced that such microstructural difference in connection with $\delta$-ferrite formation between two steels was an important factor to understand better high temperature creep properties in $3 \%$ Co steel rather than those in Co free steel.
\end{abstract}

KEY WORDS: Co; high Cr ferritic steels, creep properties; $\delta$-ferrite; inter-metallic compounds; MX.

\section{Introduction}

It is known that Co is one of the important alloying elements to suppress $\delta$-ferrite formation during high temperature normalizing process in high $\mathrm{Cr}$ ferritic steels with 9-12 mass \% $\mathrm{Cr}$ for mainly turbine usage. ${ }^{1)}$ Because it is hard to obtain simple martensitic structure without $\delta$-ferrite in recent advanced heat resisting steels in which Mo tend to be replaced by $\mathrm{W}$ for improving high temperature creep strength. $^{2-4)}$ On the other hand, it has been reported that adding 2-3\% Co drastically improves short-term creep strength, while long-term creep properties tend to deteriorate around $923 \mathrm{~K}^{5,6)}$

Therefore, it is very important to know what the concrete mechanism that $\mathrm{Co}$ bearing in high $\mathrm{Cr}$ ferritic steels affects creep properties at a high temperature in order to optimize alloy design. However, its mechanism is not yet clear because most of added Co presents as solid solution in matrix even after prolonged creep testing. That is to say, Co may indirectly affect on microstructural change in the complicated martensitic structure. For example, Igarashi et al. suggested that $\mathrm{Co}$ accelerated one of inter-metallic compounds, $\mu$ phase in $9 \mathrm{Cr}-2.6 \mathrm{~W}-\mathrm{Mo}, \mathrm{Nb}, \mathrm{V}$ steels ${ }^{7)}$ and Hald et al. indicated that various precipitation phenomena should be retarded in the Co bearing steel because the volume diffusion coefficient was dependent on Curie temperature $\left(T_{\mathrm{c}}\right)$ that was increased by Co. ${ }^{8)}$

In this paper, the effect of adding Co to microstructure was studied in detail using simply two kinds of steels; one with and one without Co. The difference in various precipitation behaviors between the two steels after tempering stage was focused on, and then the cause of change in creep properties of the steels was discussed.

\section{Experimental Procedure}

Two ingots with and without Co were prepared by vacuum induction remelting method. These ingots were hot worked down to $15 \mathrm{~mm} \phi$ bars and normalized for $0.5 \mathrm{~h}$ at $1373 \mathrm{~K}$ followed by air-cooling.

Some coupon were cut from normalized bars and heated for $1.0 \mathrm{~h}$ at various temperatures ranging from $773-1113 \mathrm{~K}$ to know the tempering behavior of these steels. Remaining bars were tempered for $4.0 \mathrm{~h}$ at $1043 \mathrm{~K}$ to investigate creep properties and microstructures. Moreover, the two steels were aged at $923 \mathrm{~K}$ for $1000 \mathrm{~h}$ to compare the distribution of precipitates after long-term keeping.

Table 1 shows chemical compositions of these steels used. The base composition, $9 \mathrm{Cr}-3.3 \mathrm{~W}-0.2 \mathrm{~V}-0.08 \mathrm{C}-$ $0.05 \mathrm{~N}-0.005 \mathrm{~B}$, is almost same with exception of Co.

The creep testing was conducted at $923 \mathrm{~K}$ with stress, $120 \mathrm{MPa}$ using 5-D specimen. An ICP analysis was used to measure quantitative precipitation behavior of metallic elements in two different extracted residues from tempered steels. One was extracted using $10 \% \mathrm{Br}-\mathrm{Methanol}$ for mainly stable nitrides and the other was extracted using 
Table 1. Chemical composition of steels used (mass $\%$ ).

\begin{tabular}{ccccccccc}
\hline & $\mathrm{C}$ & $\mathrm{Cr}$ & $\mathrm{W}$ & $\mathrm{Co}$ & $\mathrm{V}$ & $\mathrm{Nb}$ & $\mathrm{N}$ & $\mathrm{B}$ \\
\hline & & & & & & & & \\
$3 \% \mathrm{Co}$ & 0.082 & 9.16 & 3.27 & 2.94 & 0.19 & 0.050 & 0.058 & 0.0047 \\
\hline & & & & & & & & \\
Co-free & 0.073 & 8.93 & 3.23 & - & 0.19 & 0.046 & 0.051 & 0.0050 \\
\hline
\end{tabular}

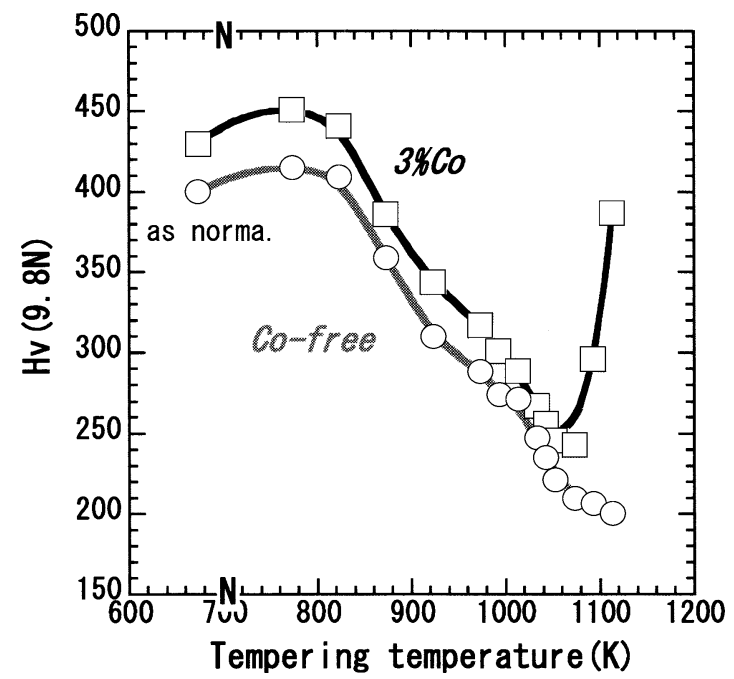

Fig. 1. Softening curves of $3 \%$ Co and Co free steels.

$10 \%$ Acetyil-Aceton for carbides as well as nitrides. Microstructures of the tempered steels were studied by a SEM (Hitachi S-4700) at $7.0 \mathrm{kV}$ and a TEM (Hitachi HF2000) at $200 \mathrm{kV}$. Energy Dispersed X-ray (EDX) analysis in the TEM was conducted using about a $5 \mathrm{~nm}$ electron probe. For both electron microscopes, specimens were prepared by an electro-chemical polishing method using solution, $10 \%$ perchloric acid methanol, at $253 \mathrm{~K}$. 'Thermo Calc.' was also used for estimating equilibrium phase at elevated temperatures.

\section{Results}

\subsection{Microstructure}

Figure 1 shows hardness change with aging temperatures for two steels with $3 \% \mathrm{Co}$ and without Co. It is found that softening behaviors are similar between two steels with exception over 1050 K. Figures 2(a) and 2(b) show optical micrographs of the tempered steels. It is clear that the steel with $3 \%$ Co represents typical tempered lath martensitic structure. On the other hand, Co-free steel has a different structure with some equiaxed grains in it. For $3 \%$ Co steel, prior austenite grain size was around $50 \mu \mathrm{m} \phi$. On the other hand, it decreased to less than $30 \mu \mathrm{m} \phi$ in the Co-free one. Mole fraction of equilibrium phase calculated using Thermo-Calc. existence of about $8 \% \delta$-ferrite is estimated in Co-free steel at normalization temperature as shown in Table 2.

\subsection{Creep Properties}

Figures 3(a) and 3(b) show the creep properties at 923 $\mathrm{K} / 120 \mathrm{MPa}$ for both steels. Figure 3(a) shows the change in creep rate corresponding to testing time for $3 \% \mathrm{Co}$ and Cofree steels. Although both curves represent a similar feature that has constant decreasing in a transient region down to
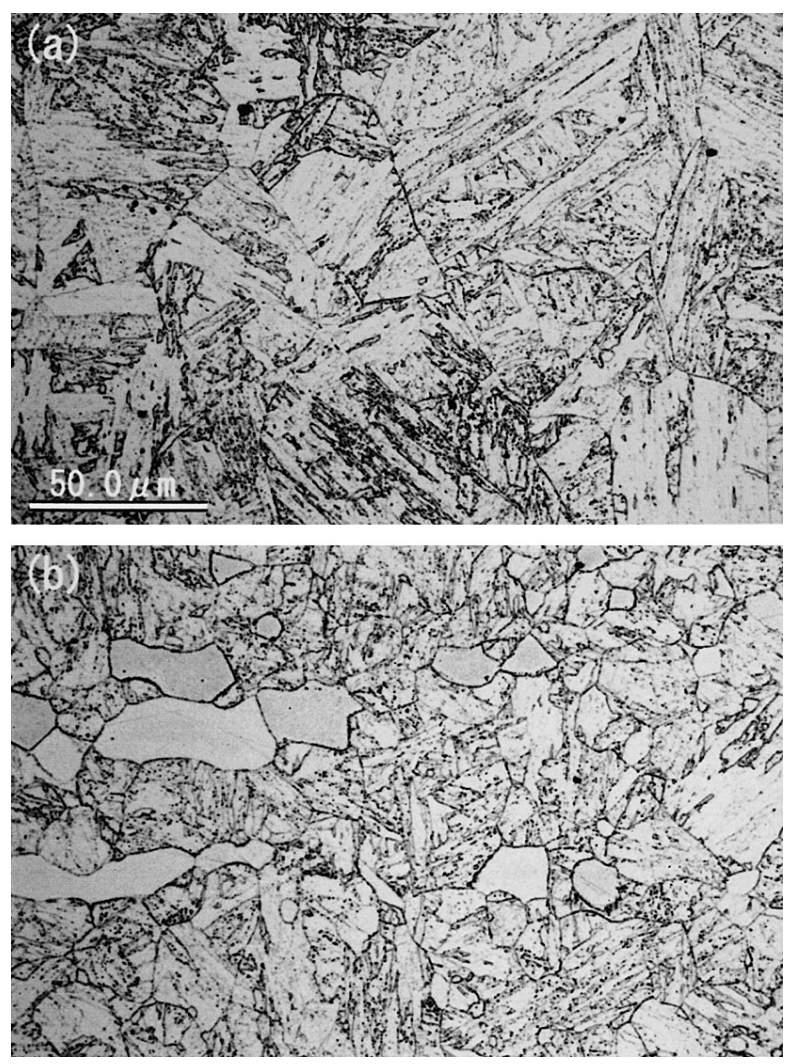

Fig. 2. Optical micrographs of (a) $3 \%$ Co and (b) Co free tempered steels.

Table 2. More concentrations of the equilibrium phases at $1373 \mathrm{~K}$ calculated by Thermo-Calc. for two steels studied.

\begin{tabular}{|c|c|c|c|}
\hline & fcc & bcc & MX \\
\hline $3 \%$ Co & 99.8 & 0 & 0.2 \\
\hline Co free & 91.3 & 8.6 & 0.1 \\
\hline
\end{tabular}

minimum values and turning to the accelerating stage, the steel with $3 \%$ Co has lower minimum creep rate and longer time to rupture rather than Co-free steel. Figure 3(b) is a different plot of creep rate against creep strain. It is clear that characteristic creep strain as indicated arrows at the minimum value of creep rate, becomes smaller in the $3 \%$ Co steel rather than Co-free one.

\subsection{Quantitative Analysis of Precipitation}

In order to compare precipitation behavior between $3 \%$ $\mathrm{Co}$ and Co free steels, metallic elements were quantified using extracted residue obtained from tempered steels. Figure 4(a) shows amount of $\mathrm{Fe}, \mathrm{Cr}$ and $\mathrm{W}$ as carbides and some inter-metallic compounds. In general, inter-metallic compounds such as Laves phase never precipitate in the steel with this tempering at $1043 \mathrm{~K}$. Therefore, these metallic elements are thought to be corresponding to the precipitation of $\mathrm{M}_{23} \mathrm{C}_{6}$ at least in the $3 \% \mathrm{Co}$ steel. In fact, mass concentrations of these elements are in good agreement with the equilibrium value estimated by Thermo-Calc as shown in Table 3. Figure 4(b) shows the amount of $\mathrm{Nb}, \mathrm{V}$ and $\mathrm{Cr}$ as MX type carbonitrides. Amounts of these two elements as carbide are derived from subtraction between two 

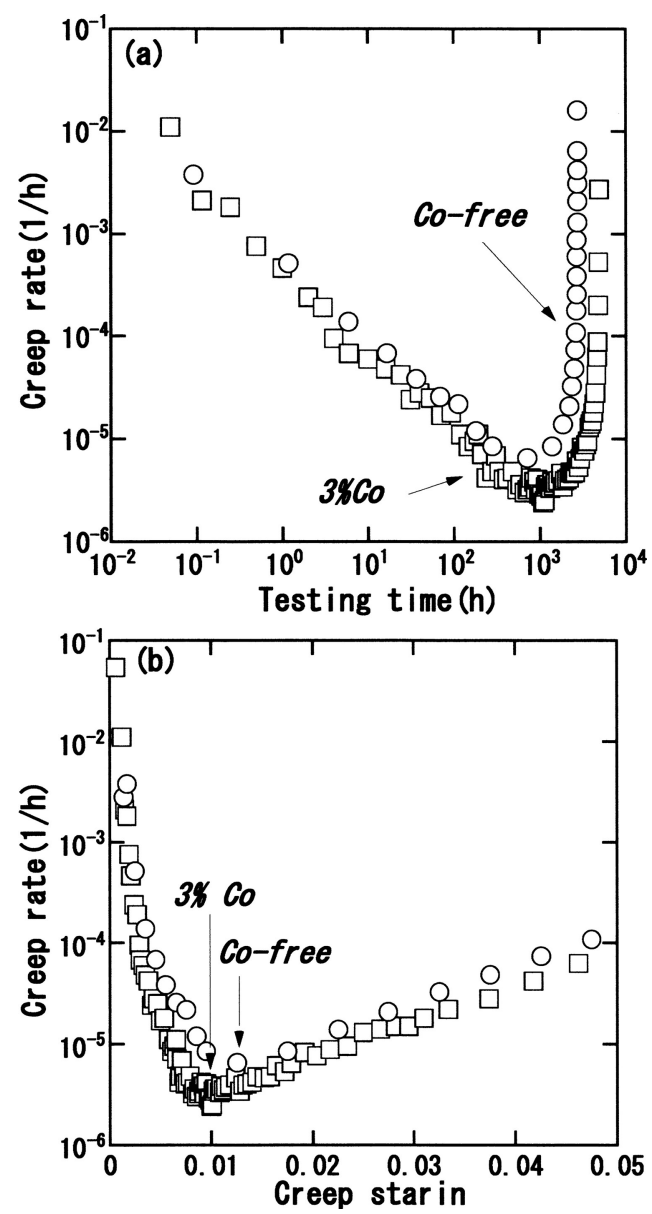

Fig. 3. Comparison in creep properties between $3 \% \mathrm{Co}$ and Co free steels at $923 \mathrm{~K} / 120 \mathrm{Mpa}$. (a) creep rate-time curves in logarithmic plots and (b) creep rate-creep strain curves.

quantitative results of extracted residues obtained by different solution, $10 \% \mathrm{Br}-\mathrm{Methanol}$ and $10 \%$ Acetyl-Aceton. Amount of Metallic elements as MX clearly increases in the Co free steel and it seems to be due to increasing of $\mathrm{V}$ and $\mathrm{Cr}$ as nitride or carbonitride. In this analysis, $\mathrm{Cr}$ as nitride is considered $\mathrm{MX}$, while $\mathrm{Cr}$ as carbide is regarded as $\mathrm{M}_{23} \mathrm{C}_{6}$.

\subsection{Distribution of Precipitates in Tempered Steels}

Firstly, the difference of microstructure with exception of $\delta$-ferrite formation between two steels was studied using SEM. Figures 5(a) and 5(b) represent backscattered electron images (BEI) of the two steels after tempering. Although usual secondary electron image (SEI) reflects surface fine structure, BEI enhances crystallographic channeling contrast and averaged atomic number contrast (Z-contrast). Therefore, fine precipitation of $\mathrm{M}_{23} \mathrm{C}_{6}$ and various boundaries such as packet and block in a large prior-austenite grain are clearly seen in Fig. 5(a). On the other hand, an equiaxed grain with no contrast change presents in Fig. 5(b). Moreover, very bright large blocky precipitates are present at the interface between this grain and surrounding martensitic structure. This equiaxed grain is thought to be $\delta$-ferrite from Fig. 2(b). Large precipitates are probably inter-metallic compounds with $\mathrm{W}$ such as Laves phase. Although precipitation could not be detected within $\delta$-ferrite region in Fig. 5(b), many very fine precipitates were ob-
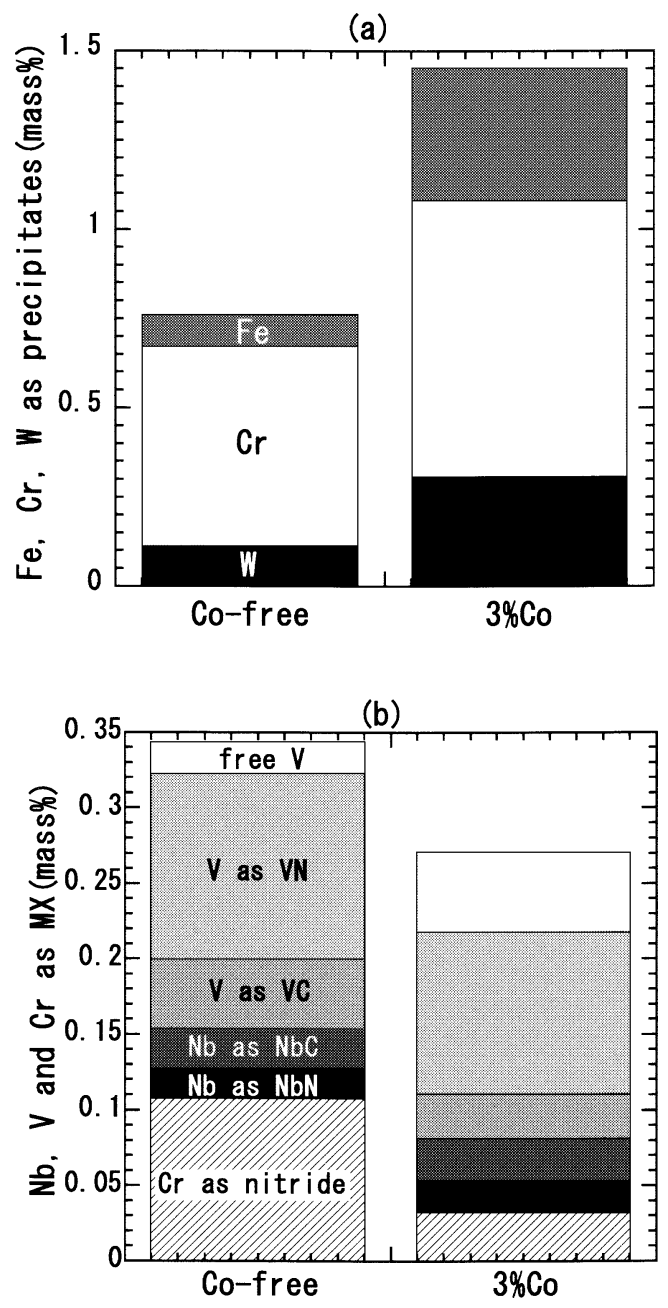

Fig. 4. Comparison in quantitative values of the metallic elements between Co free and 3\% Co and steels after tempering. (a) $\mathrm{Fe}, \mathrm{Cr}$ and $\mathrm{W}$ as precipitates and (b) $\mathrm{Nb}, \mathrm{V}$ and $\mathrm{Cr}$ as $\mathrm{MX}$ former.

Table 3. Mass $\%$ of $\mathrm{Fe}, \mathrm{Cr}$ and $\mathrm{W}$ as $\mathrm{M} 23 \mathrm{C} 6$ derived from quantification of extracted residue of the tempered $3 \%$ Co steel and the result of calculation using Thermo-Calc. at $1043 \mathrm{~K}$.

\begin{tabular}{|c|c|c|c|}
\hline & $\mathrm{Fe}$ & $\mathrm{Cr}$ & $\mathrm{W}$ \\
\hline Experiment & 25.0 & 54.4 & 20.6 \\
\hline Thermo-Calc. & 25.7 & 53.0 & 21.3 \\
\hline
\end{tabular}

served in a high-magnified SEI as exemplified in Fig. 6. Platelet or rod type precipitates are present with characteristic direction inside $\delta$-ferrite. Its average size is $10 \mathrm{~nm}$ width and less than $100 \mathrm{~nm}$ length. These fine precipitates are thought to be MX composed with light elements because Z-contrast of this precipitation is very weak in BEI. For $\mathrm{M}_{23} \mathrm{C}_{6}$, there is not any notable difference in distribution between the two tempered steels in SEM observation.

\subsection{Precipitation Detail in Co-free Steel}

Secondly, TEM observation was conducted to clarify more detail of precipitation in Co-free steel. Figures 7(a) and 7(b) show a TEM micrograph involving $\delta$-ferrite region and a typical EDX spectrum obtained from a large 

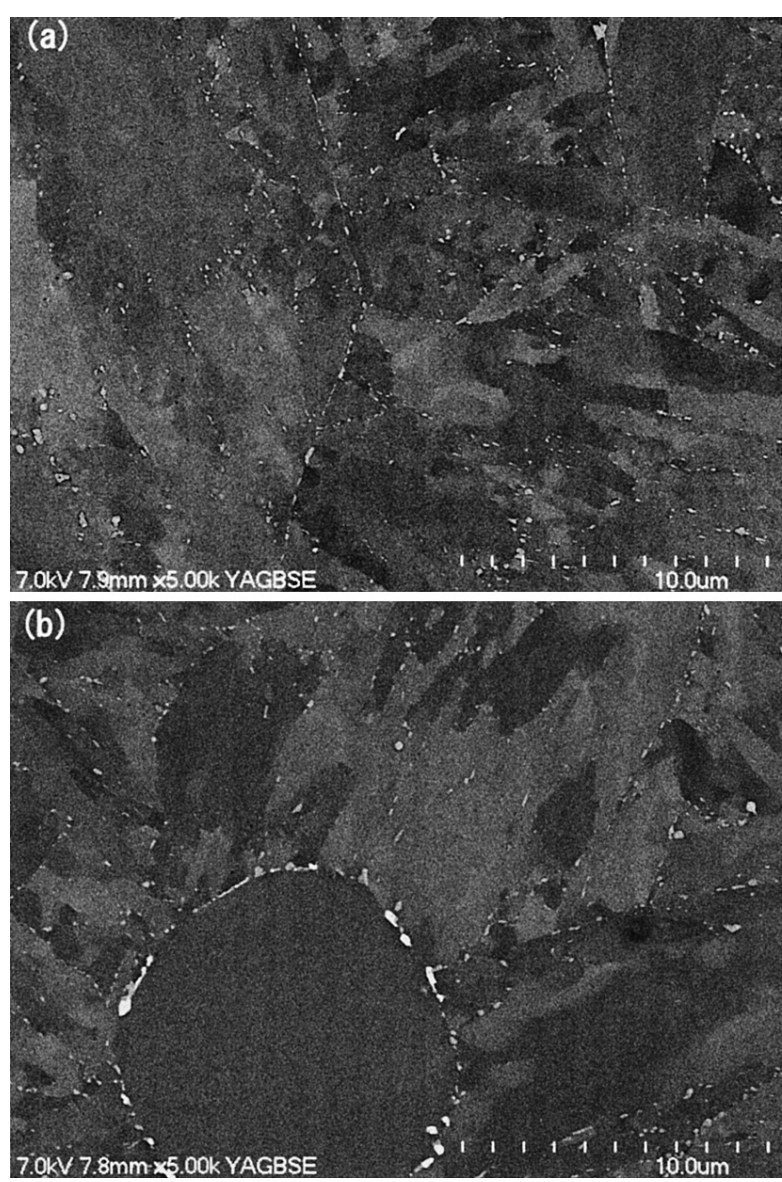

Fig. 5. Backscattered electron images of (a) $3 \% \mathrm{Co}$ and (b) Co free tempered steels.

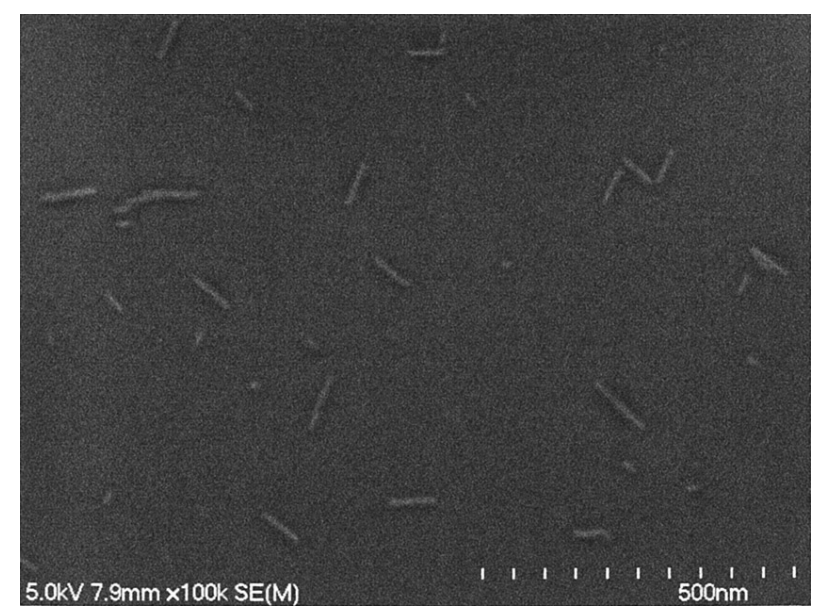

Fig. 6. A high-magnified secondary electron image of fine precipitates observed within an equiaxed gain in the Co free steel after tempering.

precipitate as indicated white arrow in Fig. 7(a). Assuming no matrix effect in TEM/EDX analysis can derive atomic composition of this large precipitate inside Fig. 7(b). This value is very similar to that of $\chi$ phase $\left(\mathrm{Fe}_{62} \mathrm{Cr}_{21} \mathrm{~W}_{17}\right)$. However, compositions of some other precipitates are close to that of Lave phase $\left(\mathrm{Fe}_{56} \mathrm{Cr}_{11} \mathrm{~W}_{33}\right)$.

Figures 8(a) and 8(b) show a high magnified TEM micrograph inside $\delta$-ferrite region and normalized EDX spectra obtained from $\delta$-ferrite and region involving a fine precipitate. This TEM micrograph is taken from near $[001]_{\mathrm{bcc}}$
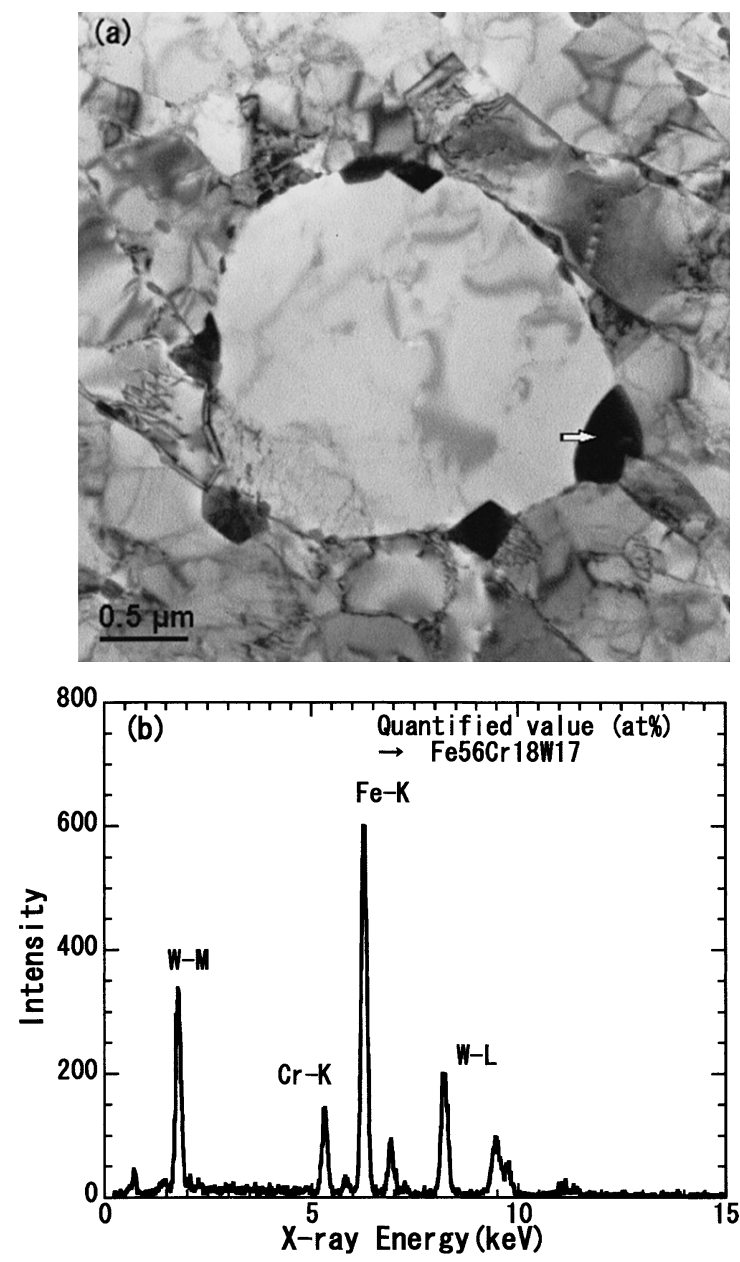

Fig. 7. (a) A TEM micrograph of blocky large precipitates found surrounding an equiaxed grain in Co free steel after tempering. (b) A typical TEM/EDX spectrum obtained from one as indicated by an arrow in (a).

direction to avoid strong diffraction contrast with zone axis. It is clear that fine precipitates with high density are in good agreement with SEM observation as shown in Fig. 6. A selected area diffraction pattern inside Fig. 8(a) is taken from just $[001]_{\mathrm{bcc}}$ zone axis. This pattern has a very diffuse streak at fundamental spots along $\langle 110\rangle$ direction. Such fine precipitates with high density never present in surrounding martensitic region. Although it is hard to avoid matrix effect in TEM/EDX analysis even with $5 \mathrm{~nm}$ electron probe, it is clearly seen that $\mathrm{V}$ enrich to fine precipitate from comparison between two spectra that is normalized by intensity of Fe-K peak as shown in Fig. 8(b).

\subsection{Distribution of Precipitates in Long-term Aged Steels}

There are a few reports about Co condition of presence in high $\mathrm{Cr}$ ferritic steels with Co. Generally, added Co is thought to be present as solution in matrix after tempering and long-term creep testing. It is also confirmed that solution of Co to $\mathrm{M}_{23} \mathrm{C}_{6}, \mathrm{MX}$ and inter-metallic compounds is negligible in this study at tempered stage. On the other hand, it has been pointed out that precipitation behavior of inter-metallic compounds at long-term creep stage should be changed by adding Co. ${ }^{7,8}$

Therefore, effect of Co on precipitation of $\mathrm{M}_{23} \mathrm{C}_{6}$ and inter-metallic compounds is compared using steels aged at 

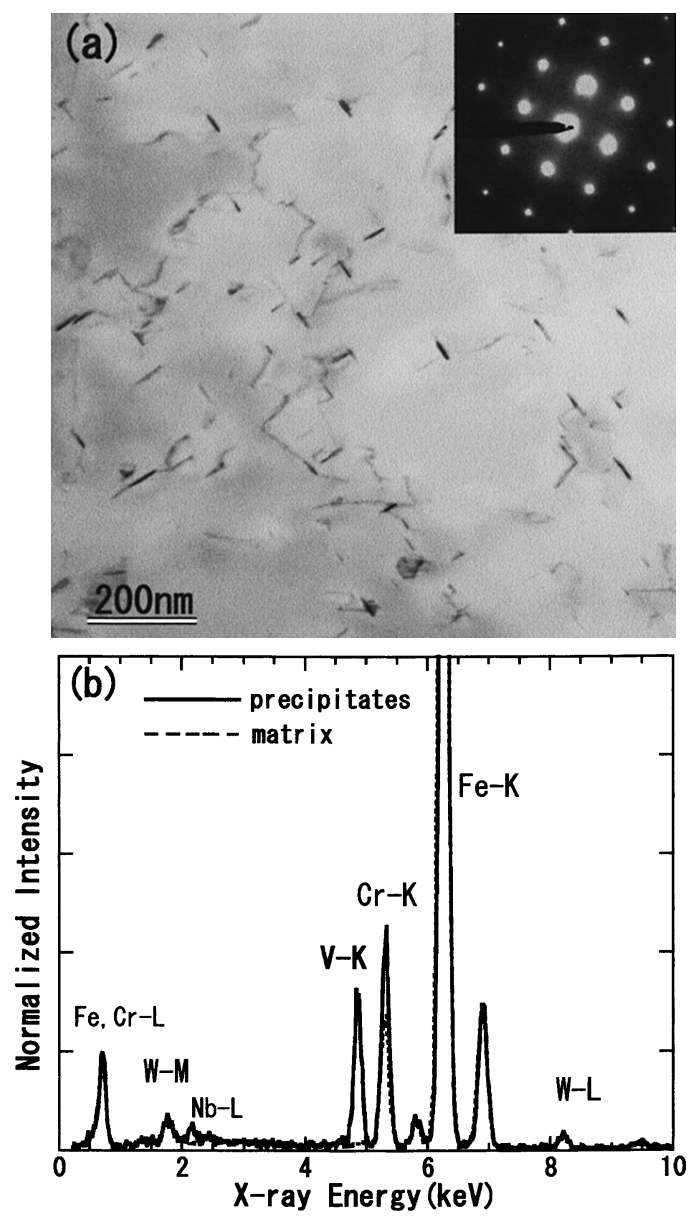

Fig. 8. (a) A TEM micrograph showing fine precipitates in the equiaxed grain under nearly [001 $]_{\text {bcc }}$ direction and its selected area electron diffraction pattern inside. (b) Comparison of normalized TEM/EDX spectra between matrix and precipitates by analysis with about $5 \mathrm{~nm} \phi$ electron probe.

$923 \mathrm{~K}$ for $1000 \mathrm{~h}$. Figures 9(a) and 9(b) show BEI of these aged steels with and without Co. The fields of view without $\delta$-ferrite region are selected to avoid heterogeneous precipitation in Fig. 9.

It is clear that precipitation of inter-metallic compounds with high brightness increases to almost same degree in both aged steels. However, there is no remarkable difference in amount of inter-metallic compounds using image processing for Fig. 9. Distribution and each size of fine $\mathrm{M}_{23} \mathrm{C}_{6}$ with lower brightness in Fig. 9 did not change between the two steels and Co content in the matrix of $3 \% \mathrm{Co}$ steel is close to added level at this aging stage.

\section{Discussion}

\subsection{Effect of Co on Microstructures}

It is well known that austenite-stabilizing alloying elements such as $\mathrm{Co}, \mathrm{Ni}$ and $\mathrm{Cu}$ are useful to suppress $\delta$-ferrite formation when advanced high $\mathrm{Cr}$ ferritic steels are exposed to high temperature normalization. The most outstanding difference in microstructure in this study is the presence of $\delta$-ferrite in Co free steel as shown in Figs. 2 and 5. Moreover, it is clear that $\delta$-ferrite formation strongly affects the prior austenite grain size in the initial tempered martensitic structure. This indicates that dispersed $\delta$-ferrite


Fig. 9. Backscatterd electron images of steels aged for $1000 \mathrm{~h}$ at 923 K. (a) $3 \%$ Co steel and (b) Co free steel.

is probably an obstacle for growing of austenite grain at normalization temperature.

In addition to this $\delta$-ferrite formation, heterogeneous precipitation of inter-metallic compounds and MX seems to be a very important difference in microstructure. Both phenomena are a natural corollary of non-uniformity in alloying elements such as $\mathrm{W}, \mathrm{Cr}$ and $\mathrm{V}$ during normalization in the Co free steel. It is supposed that initial partitioning of these ferrite-stabilizing elements to $\delta$-ferrite region results in heterogeneous precipitation. On the other hand, such fluctuation of alloying elements is hard to occur in the steel without $\delta$-ferrite. Therefore, no unusual precipitation behavior was seen in the tempered steel with $3 \% \mathrm{Co}$.

\subsection{Effect on Creep Properties by Microstructural Change}

It is usually pointed out that the steel with fine grain deteriorates its creep property rather than steel with coarse grain. ${ }^{9)}$ This phenomenon can be explained by accelerated recovering during long-term keeping at elevated temperatures because nucleation and individual growth of precipitates easily occur assisted by preferential diffusion at large angle grain boundaries in the steel with finer prior-austenite grains. Therefore, the notable difference in initial grain size of the steels studied may be one factor in yielding different creep properties. However, dominant precipitation behaviors of $\mathrm{M}_{23} \mathrm{C}_{6}$ and inter-metallic compounds are similar between the two steels, at least 1000 h-aged materials in this study as shown in Fig. 9.

By consideration of Figs. 3(a) and 3(b), creep deformation within the transient creep region was effectively sup- 
pressed in the steel with 3\% Co rather than Co free one. This is typical feature of precipitation strengthening of matrix with fine MX in the advanced heat resisting steels. ${ }^{10}$ ) Although total amount of MX type carbonitrides increased in Co free steel as shown in Fig. 4(b), they were localized inside $\delta$-ferrite region as exemplified in Fig. 6 and Fig. 8(a). This fact seems to be disadvantageous for achieving better creep resistance with homogeneous dispersion of fine precipitation in the martensitic structure. Furthermore, there is not remarkable change in precipitation of intermetallic compounds at the region without $\delta$-ferrite between steels studied, however heterogeneous precipitation of them after tempering stage in the Co free steel may influence its creep property.

\section{Conclusion}

The effect of adding Co to microstructure in $9 \% \mathrm{Cr}$ ferritic steel was studied in detail in order to better understand the drastic difference in creep properties between 3\% Co and Co free steels. It was concluded that some important factors in microstructure were clarified to explain the deterioration in creep property of Co free steel as follows.

(1) Finer and heterogeneous microstructure with $\delta$-ferrite was clearly found in Co free steel while typical homogeneous tempered martensitic structure was obtained in $3 \%$ Co steel.

(2) It was found that inter-metallic compounds tended to precipitate at the boundaries between $\delta$-ferrite and surrounding martensitic region even at tempering stage.

(3) Localized precipitation of fine MX with very high density was confirmed within $\delta$-ferrite region in Co free steel.

(4) There was not a notable difference in distribution and size of $\mathrm{M}_{23} \mathrm{C}_{6}$ and inter-metallic compounds between two steels in this study with exception of heterogeneous early precipitation of inter-metallic compounds in Co free steel.

It was supposed that superior creep properties in 3\% Co steel rather than Co free one was obtained by suppressing $\delta$-ferrite. However, related important microstructural changes between two steels such as size of prior austenite grain, heterogeneous precipitation of inter-metallic compounds and MX proved also important to understand the difference in creep strength.

\section{REFERENCES}

1) T. Fujita: Tetsu-to-Hagané, 49 (1963), 1561

2) M. Shiga, H. Fukui, S. Takahashi, Y. Maeno and T. Fujita: $C A M P$ ISIJ, 5 (1992), 2033.

3) T. Uehara, R. Watanabe and T. Fujita: CAMP-ISIJ, 6 (1993), 712.

4) K. Hidaka, H. Fukui, S. Nakamura, R. Kaneko, T. Fujita and Y. Tanaka: CAMP-ISIJ, 11 (1998), 436.

5) T. Tsuchiyama and T. Fujita: Tetsu-to-Hagané, 65 (1979), S417.

6) S. H. Ryu, J. Yu and B. S. Ku: Proc. of the 5th Int. Charles Parsons Turbine Conf., IOM, London, (2000), 472.

7) M. Igarashi and Y. Sawaragi: CAMP-ISIJ, 9 (1996), 566.

8) J. Hald and S. Straub: Proc. of Materials for Advanced Power Engineering, Part I (6th Liege Conf.), Forschungszentrum Jülich GmbH, Jülich, (1998), 155.

9) T. Hasegawa, T. Muraki and Y. Okamura: CAMP-ISIJ, 12 (1999), 1320 .

10) K. Yamada, M. Igarashi, S. Muneki and F. Abe: ISIJ Int., 42 (2002), 779 